\title{
Making Space for Social and Emotional Learning in Science Education
}

\author{
Erin Ingram ${ }^{1 *}$, Kristie Reddick ${ }^{2}$, Jessica M. Honaker ${ }^{2}$ and Gwen A. Pearson ${ }^{3}$ \\ ${ }^{1}$ Department of Biological Systems Engineering, Institute of Agriculture and Natural Resources, University of Nebraska-Lincoln, \\ Lincoln, NE, United States, ${ }^{2}$ Solpugid Productions LLC, DBA The Bug Chicks, Cincinnati, OH, United States, ${ }^{3}$ Department of \\ Entomology, Purdue University, West Lafayette, IN, United States
}

Social-emotional learning (SEL) is known to improve student outcomes but is rarely combined with STEM. In this paper we present an action research study to examine the impact of a STEM + SEL curriculum intervention to address a real-world school conflict. One hundred sixth-eighth graders and four teachers participated in an in-person facilitation of a SEL Arthropod curriculum, DIFFERENT. After the intervention, students completed open-ended couplet statements about arthropod behavior, tarantulas, and humans designed to measure sentiment change. Answers were manually coded using inductive coding on a scale of negative (1) to positive (5). Statement sentiments significantly shifted from negative to neutral and negative to positive for all three questions. Neutral to positive shifts were only significant for the couplet statements about arthropod behavior. This study reports the first confirmed instance of successful use of arthropods for SEL within a curriculum that integrates students' social-emotional skills within a science classroom.

Reviewed by: Jinjin Lu, China University of Geosciences, Keywords: social-emotional learning, arthropods, middle school, science education, integrated learning, interdisciplinary, entomology

Wing Yee Lo,

Woosong University, South Korea

\section{INTRODUCTION}

*Correspondence: Erin Ingram eingram3@unl.edu

Specialty section:

This article was submitted to Educational Psychology,

a section of the journal

Frontiers in Education

Received: 21 May 2021

Accepted: 26 July 2021

Published: 17 August 2021

Citation:

Ingram E, Reddick K, Honaker JM and Pearson GA (2021) Making Space for Social and Emotional Learning in Science Education.

Front. Educ. 6:712720. doi: 10.3389/feduc.2021.712720

In the Pacific Northwest, a suburban options-based middle school program (OBMP) focuses on environmental science through integration with other subjects. These students arrive very early in the day, and their school day ends earlier than normal. This program is housed inside a traditional middle school (TMS) whose hours begin and end later each day. In addition, the OBMP students leave the grounds once a week for environmental community service projects.

The TMS students see this as a fun weekly "field trip," and due to the segregated nature of the student populations between the two schools, misunderstandings about the nature of the OBMP program led to increased tensions, bullying, and emotional strife.

We were invited by the OBMP to lead their students through a science and social-emotional learning (SEL) curriculum called DIFFERENT, where students challenge their perception of themselves, others, and the natural world by learning about arthropods.

Given the situation at the school, we had two key questions:

1. Do arthropods provide the spark of engagement necessary to successfully integrate STEM content and SEL?

2. Can entomology be used to build empathy not only for arthropods, but also people with differing experiences? 
The intent of this study was to pilot a curriculum to address conflict and build social-emotional competencies in a science education context.

Social-emotional learning (SEL) is defined in many ways in the research literature, and includes subfields of character or civic education, social skills, life skills, "soft" skills, and 21st century skills (Jones and Kahn, 2017). While SEL may be difficult to cleanly define, it is a useful concept that encapsulates a multifaceted assortment of non-academic knowledge, skills, and attitudes related to self-management, relationship building, and responsible decision making.

Teaching SEL is a proactive approach to dealing with classroom management issues. Rather than responding to students' negative emotions or antisocial behaviors after they become problematic, educators help develop students' SEL skills as life tools to thrive in school and beyond. SEL programs have been found to contribute to gains in social-emotional skills and attitudes about self, others, and school, improved grades and academic performance on standardized tests, and a reduction in negative student conduct behaviors such as school suspensions and drug use (Durlak et al., 2011; Taylor et al., 2017). In addition, the return on investment is impressive, with high quality SEL programs yielding an estimated 11:1 return on dollars invested (Belfield et al., 2015).

High-quality SEL programs include four recommended elements, known by the acronym SAFE: Sequenced, Active, Focused, and Explicit (Durlak et al., 2010; Durlak et al., 2011). Programs result in consistently positive outcomes when they:

1. use a sequenced step-by-step training approach

2. emphasize active learning in which youth practice new skills

3. focus specific time and attention on personal and social skill training

4. clearly define their goals in explicit rather than general terms.

Implementation is also key to success and requires training and on-going support for facilitators (CASEL, 2013; CASEL, 2015).

While SEL is clearly important in modern pedagogy, integration of SEL into STEM (Science, Technology, Engineering, and Mathematics) subjects may be viewed as incompatible. In this paper, we argue science and emotions are not irreconcilable, and should not be separated. In fact, we argue science and social-emotional learning are synergistic, and lead to greater understanding when combined.

Implementation of SEL into schools is often done as a separate class or section, rather than integrated into existing subject matter. While this does bring focus to SEL as an important topic, it does not support the reality that social emotional concepts are a part of every aspect of our lives (Zins, 2004). As Brown (2021) put it, we are not teaching science, we are teaching people.

To ask students to leave their emotions and social connections at the door and engage only rational thinking in the science classroom is not a reasonable expectation, nor should it be encouraged. As science educators we need to address emotions because (like it or not), emotions influence learning outcomes in the science education classroom (Pekrun and Stephens, 2012). Students are always experiencing emotions in STEM; disciplinespecific emotions (Goetz et al., 2006), topic emotions (Broughton et al., 2013), or academic emotions related to classroom learning contexts (Pekrun et al., 2002; Pekrun and Stephens, 2012). Whether it is test anxiety or sadness when studying species extinction, emotions are always in the room.

Emotion plays a key role in decision making (ImmordinoYang and Damasio, 2007). Therefore, if we want to influence decision making, we must be willing to recognize and grapple with the role emotions play in our-and our students'-decision making processes. Ideally, we want school science to be relevant outside the walls of the classroom, and to support students in integrating scientific knowledge into their worldviews and identities (National Research Council, 2012).

While there are many ways to teach SEL in the K-12 classroom (CASEL, 2013; CASEL, 2015), embedding SEL within academic subjects can contribute to a systemic approach to teaching social-emotional skills. In addition, the integration of SEL with a required subject supports teachers and eases the burden of having to fit new content into an already packed academic schedule. Teachers can struggle to find the time and bandwidth to teach isolated SEL curriculum and it can feel less forced and inauthentic than when integrated into existing lessons.

Can you imagine bringing a tarantula or a large insect into a classroom and students NOT having an emotional response? Some K-12 educators see the value of using arthropods as model organisms in their science classrooms and acknowledge that student engagement increases due to students' strong emotional response to these animals (Ingram, 2019). The unexpected can activate a powerful range of emotions. Even if the emotion is "ick!," these feelings create an entry point to discuss empathy, respect for differences, thoughtful inquiry, and to model how to ask questions that are curiosity-based rather than judgement-based.

Standards-based science education ensures that instruction must include particular content, but does not prescribe how this content must be taught (National Research Council, 2012; NGSS Lead States, 2013). Many secondary science teachers report having the freedom to select instructional practices and curriculum materials that best suit their needs (Banilower et al., 2018). This includes the freedom to select from a plethora of available model organisms to teach about key science ideas such as evolution, natural selection, adaptations, and survival strategies.

By blending SEL with science content, students have the opportunity to challenge how they see themselves, others, and the natural world. One result of connecting students with nature is increased empathy for animals. This translates directly to a deeper empathy for people. Castano (2012) documents that youth who had previously acted indifferently or harmfully toward animals were better able to feel concern and empathy toward them, and subsequently toward their human peers, after an SELscience unit in their school. Interacting with animals and nature has the potential to reduce aggressive behaviors (Katcher and Teumer, 2006). 
TABLE 1 | Roadmap and phase descriptions of the DIFFERENT curriculum.

Curriculum phase

Phase 1: Videos and Self-reflection questions

Ten videos about arthropod biology and survival strategies. After watching each video, student individually answer accompanying self-reflection questions. Videos can be viewed in any order or combination (all or only a few) before moving to Phase 2. This is where live animals could be used as a supplement.

Facilitator/teacher led group discussion focusing on the self-reflection questions and arthropod connections. Teachers are provided with additional SEL materials to be used at their discretion in order to guide talks about deeper social-emotional constructs.

Phase 3: DIFFERENT action technology project

Multimedia technology project for small groups where students take direct action (empathy, tolerance, gratitude, etc.) that impacts their schools, families and communities positively based on what they learned in the videos and the discussions.

Phase 4: Student assessment

Students complete an assessment that tracks sentiment change over the course of the curriculum to determine growth and flexibility of mindset. The assessment is a mixture of short answer and a series of paired statements to complete (I used to think ... Now I think...).

\section{MATERIALS AND METHODS}

\section{Research Design}

To answer our research questions, we conducted action research (Creswell, 2012) to determine the impact that an arthropod-themed SEL + STEM curriculum intervention has on students' attitudes and perceptions not only of arthropods, but also themselves and others.

We predicted that this curriculum would result in positive emotional mindset shifts in students, while also encouraging engagement and interest in arthropods.

\section{The DIFFERENT Curriculum}

DIFFERENT: social-emotional learning using arthropods is a curriculum developed in 2019 by entomologists and educators Kristie Reddick and Jessica Honaker. It integrates arthropod biology, empathy, and self-reflection with emotional capacity building and selfmanagement. A service-learning project that encourages students to showcase their creativity and communication skills is also included. DIFFERENT is designed to challenge students' perceptions of themselves, others and the natural world.

The curriculum is designed for grades 4-12 and is matched for each grade to the Next Generation Science Standards (NGSS) (NGSS Lead States, 2013) complete with further science investigations for each matched standard. It is also aligned with the social-emotional principles and objectives outlined by CASEL (Zins and Elias, 2007).

The curriculum consists of four phases (Table 1). By placing the initial focus squarely on arthropod survival strategies, these lessons are designed to relieve some of the pressures that students can feel in traditional SEL. Because the DIFFERENT curriculum is integrated with regular science instruction, it creates a space where students have the freedom to wonder about themselves and/or the entomological subjects.

\section{Participants}

From December 2019 to January 2020, a pilot study was completed with 100 students and four teachers in four classrooms at an options-based middle school program hosted inside a traditional middle school in a suburb of a city in the Pacific Northwest. Each class had a mix of sixth-eighth graders. The OBMP is open to students across the district through an application process. The school is populated partially through a lottery system.
The demographic makeup of the OBMP is reported with the TMS in which it is hosted. The student body is $40 \%$ Hispanic, $39 \%$ White, 5\% Black/African American, 7\% Asian, 1\% Native Hawaiian/Pacific Islander, $7 \%$ Multiracial, and $<0.5 \%$ American Indian/Alaskan Native. Fifty-nine percent of students at this school receive free or discounted lunches.

\section{Procedures}

During the pilot, four videos from the DIFFERENT curriculum and their corresponding Student Self-Reflection questions were chosen: Feeling Fear, Misunderstood, What's in a Name, Mistaken Identity. Feeling Fear explains how arthropods respond to negative stimuli when they feel threatened and follows the journey of a high school student who was terrified of bugs and overcame her fear during a week-long trip to the Amazon Rainforest. Misunderstood dives into various misconceptions of arthropods and how those mix-ups can be dangerous and unhelpful. What's in a Name explores the ways that names tell us how to feel about certain animals and the power of meaning, myth and fact. Mistaken Identity explores how mimicry can go far beyond color to help arthropods successfully maneuver through their habitats.

The curriculum developer/entomological facilitator spent one full day in each classroom. All students watched the four videos and answered the Student Self-Reflection questions before moving on to class-sized group discussions about the arthropod content and their individual experiences and feelings. The facilitator then engaged the students with live arthropods, ranging from beetles to tarantulas, and helped to facilitate the group discussion along with each of the four teachers. Students then split into small groups and created short technology projects based on what they learned about arthropods, themselves, and others from DIFFERENT.

\section{Data Collection}

Students were asked to complete a 12 -item online assessment to determine sentiment change and possible change in behavior of students toward arthropods and people who are/think/look differently from them. The assessment consisted of five openended, fill-in-the-blank couplet statements, and seven short answer questions. The couplet questions are based on a style of rapid assessment used to measure change in attitude or thinking in a 
TABLE 2 | Code matrix with keywords and example student answers.

\begin{tabular}{|c|c|c|c|}
\hline $\begin{array}{l}\text { Sentiment code } \\
\text { and description }\end{array}$ & & Keywords & Example phrases \\
\hline 1-Negative & $\begin{array}{l}\text { - Gross } \\
\text { - Disgusting } \\
\text { - Killing } \\
\text { - Biting } \\
\text { - Scary } \\
\text { - Stupid } \\
\text { - Creepy }\end{array}$ & $\begin{array}{l}\text { - Startling } \\
\text { - Freakish } \\
\text { - Viscious (sic) } \\
\text { - Annoying } \\
\text { - Violent } \\
\text { - Harmful } \\
\text { - Satanic }\end{array}$ & $\begin{array}{l}\text { - "i used to think that they wanted to bite us" } \\
\text { - "Gross and disgusting" } \\
\text { - "I hate them" } \\
\text { - "i used to think they were absolutly (sic) terrifying" } \\
\text { - "just trying to go against me" }\end{array}$ \\
\hline 2-Negative neutral & $\begin{array}{l}\text { - Weird } \\
\text { - Boring } \\
\text { - Odd } \\
\text { - Strange }\end{array}$ & $\begin{array}{l}\text { - Unpredictable } \\
\text { - Normal and scary } \\
\text { - Unamused } \\
\text { - Not important }\end{array}$ & $\begin{array}{l}\text { - "A little bit strange and can be difficult to be around" } \\
\text { - "they are kind of weird because they had a different opinion." } \\
\text { - "I just did not want to hold them" } \\
\text { - "not as scared as I was" } \\
\text { - "odd because they were very different than human" } \\
\text { - "unpredictable and squirrely" }\end{array}$ \\
\hline 3-Neutral & $\begin{array}{l}\text { - Unknown } \\
\text { - Normal } \\
\text { - Different } \\
\text { - Unusual } \\
\text { - Okay } \\
\text { - Unexpected }\end{array}$ & $\begin{array}{l}\text { - Natural } \\
\text { - Fine } \\
\text { - Compound or contradictory } \\
\text { - Ftatements } \\
\text { - Fact-based statements }\end{array}$ & $\begin{array}{l}\text { - "strange but I understood it was natural but had noo [sic] Idea why" } \\
\text { - "just trying to find shade or just trying to find food." } \\
\text { - "fairly normal (at least for them)" } \\
\text { - "a necessity for the bugs" } \\
\text { - "that they have there own way of solving things" }\end{array}$ \\
\hline 4-Neutral positive & $\begin{array}{l}\text { - Compound } \\
\text { - Emore neutra } \\
\text { - Conditional } \\
\text { - Comfortable }\end{array}$ & $\begin{array}{l}\text { atements of positive and } \\
\text { to negative } \\
\text { ements ("trying to get away from us") } \\
\text { atements ("depending on the bug") }\end{array}$ & $\begin{array}{l}\text { - "have different beliefs than I do and that is ok." } \\
\text { - "Not experiencing the same things as me" } \\
\text { - "I am fascinated by them and want to learn more about them. Maybe } 1 \text { day I'll } \\
\text { - "Ket the courage to hold one." } \\
\text { - "now cool" }\end{array}$ \\
\hline 5-Positive & $\begin{array}{l}\text { - Interesting } \\
\text { - Cool } \\
\text { - Good } \\
\text { - Awesome } \\
\text { - Love } \\
\text { - Nice }\end{array}$ & $\begin{array}{l}\text { - Cute } \\
\text { - Want as pet } \\
\text { - Fascinated } \\
\text { - Proud } \\
\text { - Negation of negative words (not } \\
\text { scary, not as, etc.) }\end{array}$ & $\begin{array}{l}\text { - "Are interesting and fun to learn about." } \\
\text { - "really cool" } \\
\text { - "I like them" } \\
\text { - "I thought that tarantulas were amazing because I love spiders and I knew that } \\
\text { these ones wouldn't hurt me unless I did something that made them feel that } \\
\text { they had to protect themselves." }\end{array}$ \\
\hline
\end{tabular}

before/after mode called, "I used to think ... Now I think..." (Harvard Graduate School of Education - Project Zero, 2015).

For the purposes of this study, we chose a subset of three openended couplet statements for analysis:

1. I used to think arthropod (bug) behaviors were ... Now I think arthropod (bug) behaviors are...

2. Before these lessons, this is how I felt about these animals (picture of a tarantula shown) ... After these lessons, this is how I feel about these animals (picture of same tarantula shown)...

3. I used to feel that people who think differently from me are ... Now I feel that people who think differently from me are...

\section{Data Analysis \\ Data Cleaning}

All students completed the first two questions about arthropod behaviors and the tarantula photo $(\mathrm{N}=100)$. The question about people who think differently had 98 responses, as two of the student responses were unable to be coded because they were incomplete. Student responses were analyzed using two different methods: traditional inductive coding and artificial intelligence (AI) aided analysis.

\section{Manual Qualitative Coding}

Using an inductive coding process (Thomas, 2006), data were qualitatively coded into one of five different categories ranging from Negative (1) to Positive (5). Responses were coded based on keywords in individual student responses (Table 2).

\section{Inferential Statistical Analysis}

Responses were condensed into three broad categories (negative, neutral, and positive). For each couplet tested, a two-dimensional matrix was created to show response frequencies across the three categorical variables (negative, neutral, and positive) for the 
before (Harvard Graduate School of Education - Project Zero, 2015) and after (Now I think ... ) couplet statements.

Overall sentiment shift was analyzed using a chi-square statistical test (Dowdy et al., 2004) to identify if observed response frequencies differed from expected frequencies. A chisquare statistic was calculated for three types of sentiment shifts: Negative to Neutral, Negative to Positive, and Neutral to Positive.

\section{Artificial Intelligence-Aided Coding}

Our second method of analysis was using a prototype Artificial Intelligence program based on IBM Watson's Tonal Analysis Tool (IBM, 2021), driven by a Natural Language Processing database (Forshaw, 2019). The prototype allowed us to quantify the strength of various tones from each input statement: anger, fear, joy, sadness, analytical, confident, and tentative. By combining this with the before/after model, we measured the change ( $\Delta$ or delta) in sentiment that students communicated as a result of their participation in the curriculum. Delta is defined between -1.0 and 1.0, where negative indicates a decrease in a particular tone or sentiment, and positive indicates an increase in a particular tone or sentiment.

Though our initial goal was to utilize IBM Watson's AI solutions to code our qualitative data, it quickly became apparent that current tonal analysis methods are neither robust nor flexible enough to deal with the nuances of our dataset.

The AI was able to detect some responses that illustrated positive changes. As an example, a student responded that before the curriculum they felt "scared" about tarantulas, and after the intervention they felt "interested." The tonal analysis returned a Fear of -0.91 , where the negative indicates a decrease in the initial sentiment of fear.

Unfortunately, we found numerous anomalies in the quantitative tonal analysis that failed to reflect the actual sentiments of the students. Compound and/or contradictory statements in particular led to counterintuitive results. For example, a student reported that before the curriculum they felt "grossed out and a bit afraid" of tarantulas, and after they felt "less afraid more fasinated (sic)." However, the tonal analysis showed a Fear of -0.1 indicating an increase, rather than a decrease, of fear.

This could be the algorithm not picking up on the compound statement due to a lack of punctuation or the misspelling of the word 'fascinating.' It could also be because the word "more" is next to "afraid" even though the sentiment is very obviously a positive shift from the before statement. There are known racial and cultural biases of coding language with $\mathrm{AI}$ as well as an ageist "formal speak" bias that does not lend itself to youth vernacular, tone, and writing/typing styles (Gebru, 2020; Bender et al., 2021). Therefore, at this time, we cannot recommend using this method to determine sentiment change in students.

\section{RESULTS}

\section{Response Frequencies}

Frequencies of individual before and after responses within each category are shown in Figure 1. A frequency decrease in negative sentiment for all three couplet statements is clearly observed. The students' sentiments regarding arthropod behaviors changed from negative or neutral statements to more positive statements. This frequency shift suggests an increase in empathy towards something that some students initially perceived as a threat.

The highest number of negative student responses $(\mathrm{N}=70)$ were recorded in response to how they remembered feeling about the tarantula before the curriculum; however, after the intervention there was a clear increase in positive sentiment. Student perceptions of arthropod behaviors tended to be more negative $(\mathrm{N}=37)$ prior to intervention and skewed toward positive sentiment after.

\section{Chi-Square Analysis}

For simplicity, both negative and negative-neutral responses were pooled into a single category (Negative); and positive and positive-neutral responses were pooled into another single category (Positive). Neutral responses were categorized as such.

For the couplet "I used to think arthropod (bug) behaviors were __ now I think bug behaviors are __, responses were significantly different before and after exposure to the DIFFERENT curriculum. A greater proportion of students had a positive response for all categories of sentiment change: Negative to Positive: $X^{2}(1, N=74)=78.13, p>0.00001$, Negative to Neutral: $X^{2}(1, N=88)=23.1300, p>0.00001$; Neutral to Positive: $\mathrm{X}^{2}(1, \mathrm{~N}=38)=17.00, p>0.000037$.

For the couplet "Before these lessons, this is how I felt about these animals (picture of a tarantula shown) ... After these lessons, this is how I feel about these animals (picture of same tarantula shown) ...," before and after responses to the DIFFERENT curriculum were significantly different for shifts from Negative to Positive: $X^{2}(1$, $\mathrm{N}=91)=36.89, p<0.00001$ and Negative to Neutral: $\mathrm{X}^{2}(1, \mathrm{~N}=$ $84)=6.51, p>0.01707$. There was no significant difference in sentiment shift from Neutral to Positive: $\mathrm{X}^{2}(1, \mathrm{~N}=25)=2.76$, $p>0.09686$. This lack of significance is likely because few students initially felt neutral about tarantulas (9 out of 100).

For the couplet "I used to feel that people who think differently from me are ... Now I feel that people who think differently from me are ...", before and after responses were significantly different. A greater proportion of students shifted to a more positive response for two categories of sentiment change: Negative to Positive: $\mathrm{X}^{2}(1, \mathrm{~N}=64)=45.58, p<0.00001$ and Negative to Neutral: $X^{2}(1, N=74)=29.50, p<0.00001$.

There was no significant difference in sentiment shift from Neutral to Positive: $\mathrm{X}^{2}(1, \mathrm{~N}=58)=3.20, p 0.07369$. Student responses were coded as neutral if they used the term "normal" or "different" (Table 2). Neutral before statements often parroted the question in their answer by using the word "different". For example, "I used to feel that people who think differently from me are different." If a student thinks it's normal that people are different, then a large shift in sentiment after the curriculum is unlikely.

\section{DISCUSSION}

Findings from this study suggest that the DIFFERENT curriculum coupled with in-person facilitation is effective at 


\section{Number of Student Responses per Sentiment Code For Three Questions, Before and After DIFFERENT Curriculum Use}

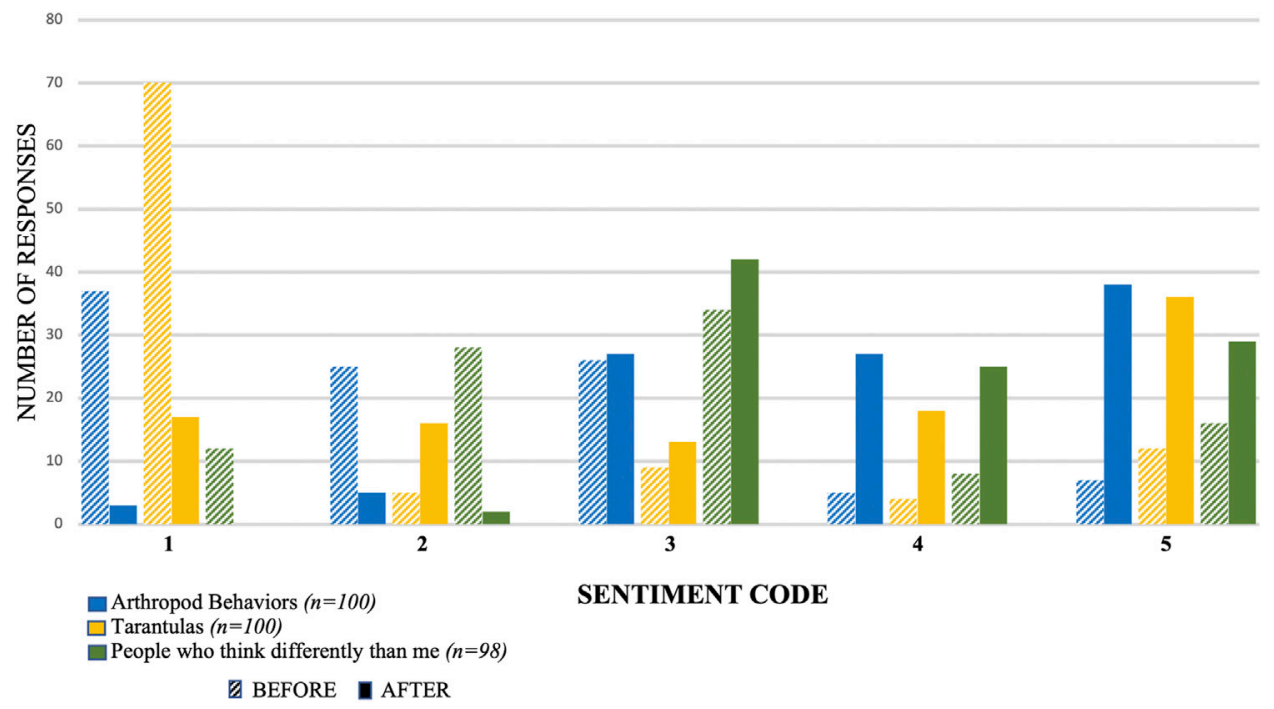

FIGURE 1 | Frequency of student responses for each sentiment category (1-5) for three statements before and after the DIFFERENT curriculum intervention. Response code categories are as follows: Negative, 1; Negative-Neutral, 2; Neutral, 3; Positive-Neutral, 4; Positive, 5.

shifting students' mindsets and beliefs. Our results provide valuable insights into how this curriculum can be used to successfully integrate SEL instruction in a science education context.

Our results are in alignment with previous studies that have acknowledged the role emotion can play in the science education classroom (Pekrun et al., 2002; Goetz et al., 2006; Pekrun and Stephens, 2012; Broughton et al., 2013). Unsurprisingly, we found that some arthropods elicit generally strong negative emotional responses; however, with explicit instructional guidance provided in the curriculum, students' sentiments shifted in a positive direction.

The shift we observed in students' sentiments about arthropods moving from generally negative to neutral or positive is noteworthy because previous studies have shown that fear can negatively impact students' ability to learn (Warr and Downing, 2000; Owens et al., 2012; Bledsoe and Baskin, 2014). On its own, this fact may discourage science teachers from presenting content such as arthropods which elicit a fear response in their students. We argue that those studies did not look at SEL integration with science programming. For the OBMP students who came into the lessons with a negative response, there was already an SEL plan in place to help transition the students from a place of fear to a more positive mindset.

Our results also suggest that arthropods are an effective vehicle for teaching SEL in a science education context. Using arthropods as model organisms in the science classroom is not a new concept (Davis, 2004). Our study advances this idea by suggesting that in much the same way that we use arthropods as a model organism to teach about science concepts such as genetics, we can also use arthropods to embed SEL in the science classroom.
Students' strong emotional responses to arthropods may be the very reason that entomology provides a successful model for integrating SEL with science content. Because of their inherent "otherness," arthropods reliably provoke some sort of emotional response in students. This provides access to feelings that are traditionally held apart or separate from scientific teaching. Though some students express disgust, this does not necessarily mean that they are not also intrigued or interested in learning more about them. It's up to the facilitator to see disgust or fear as a pathway for transforming fear into fascination and engaging in social and emotional skill building.

Traditional SEL makes humans the object of study and can cause students to feel like they are "the bug under the microscope", i.e., that their attitudes, perceptions, and worldviews are being scrutinized when they are asked to think introspectively about themselves. The DIFFERENT curriculum intentionally focuses student attention on arthropods first before exploring humans. By introducing the concept of "otherness" using arthropods, we can then help students reflect on their perceptions or attitudes about otherness in humans. We draw attention to similarities between arthropod and human behaviors to help guide students to see parallels between the arthropod experience and the human experience. Our results suggest that an intentionally integrated SEL approach can not only challenge students' perceptions of arthropods, but that it can also help students in successfully challenging their perceptions of people as well.

While our findings show positive results, we must acknowledge several limitations of our study. One clear limitation was that we were unable to enact the intervention with both the OBMP and TMS populations. In order to facilitate 
problem solving, nurture empathy, and improve relations between the two groups of students, both groups would, ideally, be involved in the intervention. Unfortunately, almost immediately after completion of the program with the OBMP, the COVID-19 pandemic necessitated school closures and the researchers were unable to work with the TMS students. Our results indicate that our intervention had an impact on the OBMP students' emotions; however, we do not know if it had real-world implications for resolving conflict between the students in these two schools.

Another challenge for our study is the layered and multifaceted nature of emotions themselves. This led to several limitations in our analysis. First, we were unable to manually code student sentiment beyond negative, neutral, or positive. As entomologists who work in outreach and teaching, we understand that students may communicate disgust, but it is often combined with curiosity or intrigue. Unfortunately, we likely need more powerful tools of analysis to reliably parse these differences and reliably identify seemingly contradictory emotions in student responses.

In addition, while great strides are being made in using AI for tonal analysis and such tools may eventually allow for a more granular analysis of student sentiment, we were unable to leverage the technology in its current form to reliably or accurately code students' responses. When multiple emotions are felt simultaneously, it is understandably challenging to clearly or concisely express these sentiments, especially as a middle school student. We see evidence of this in students' responses showing subtle or nuanced language but also in the particular vernacular and syntax used by middle school students. Perhaps future advances in AI will produce the necessary algorithms to measure not only complex emotions, but also language as it is commonly used by diverse K-12 students.

We understand that many teachers may struggle to find the time and bandwidth to teach an isolated SEL curriculum. The integration of SEL with a required academic subject may ease the burden of attempting to fit new content into an already packed academic schedule. Given the positive results of this study which successfully integrated SEL into a science education context with the DIFFERENT curriculum and in-person facilitation, we recommend the following to teachers who are considering adopting an interdisciplinary approach to SEL instruction.

First, our results highlight the need for a quality curriculum and proper professional development and teacher mentorship when initializing an interdisciplinary approach to SEL. While some teachers come to an interdisciplinary approach to education organically, others may benefit from explicit guidance on how to integrate SEL with science and other subjects along with existing learning targets and standards in order to feel confident in the foundations of this type of pedagogy. In part, this guidance may come in the form of high-quality curricular materials. We echo the recommendation of previous studies that have called for the use of curriculums that include the recommended SAFE elements (Durlak et al., 2010; Durlak et al., 2011).

In addition, professional development including the modeling of techniques for engaging students in SEL content is essential. In this intervention, the facilitator (author Reddick) used a host of techniques that helped to engage students in the science and SEL material. Part of our strategy as entomological educators and teacher trainers is to model the strategy of integrating SEL and STEM with teachers in the classroom. The strategies have been successful for us in classrooms with students and during teacher professional development.

A key part of the intervention enacted for this study involved students experiencing, first-hand, several live arthropod species with an experienced entomological educator. Because we recognize that many teachers may also have emotions about arthropods, we conducted teacher training during the curriculum pilot in order to equip teachers to reflect and process their own emotions about arthropods. While the DIFFERENT curriculum does not explicitly require the presentation of live arthropods, we cannot discount the potential impact that their use may have had on students' emotional responses during this study. For others who would like to integrate SEL into academic disciplines, we recommend being intentional about selecting engagement tools (such as live arthropods) that allow students to feel and reflect on their emotional response and connect relevant disciplinary concepts to deeper self-reflection about self, others, and community.

In the future, we would like to compare how the phrasing of questions affects sentiment and emotional change. During this study, we found that how we phrased questions matters greatly. When we asked students what they think in a before/after set of questions, they often defaulted to "fact-based" thinking, e.g.,: "I used to think that tarantulas didn't have silk and now I think they do." In later tests of the curriculum, we shifted to "I used to feel.../ Now I feel..." statements, which guide student responses away from their tendency toward right/wrong answers and fact-based responses to more values/emotions-based answers.

We were surprised at how readily students shared the answers to their individual reflection questions to Phase 1 of the curriculum. They were excited to build on other students' responses in Phase 2 to find shared experience. The reflection questions served as a strong foundation for the group discussion pieces and gave students the opportunity to approach the experience from different points of view; at the same time, they were open and able to consider new points of view. They were realizing that different points of view/experiences exist and wanting to explore those differences in real time during the class discussions. In the future, we would like to find a way to capture that moment of discovery.

In future studies, we would like to explore the potential for this intervention to impact students' later decisions and behaviors. This may be accomplished by modifying the assessment items slightly from the couplet statement, "I used to feel.../Now I feel...," to a triplet statement which also includes the statement "because of this, I will...". This information along with an analysis of students' DIFFERENT Action Technology Projects from Phase 3 of the curriculum may provide evidence for a link between sentiment change and students' decisions and actions.

\section{CONCLUSION}

In this study, we found arthropods to be a useful engagement tool for successfully integrating science content and SEL in order to 
build empathy not only for arthropods, but also for people with differing experiences. While this intervention was conducted in a science education context, we feel it is possible to tie SEL into many different academic disciplines. We never stop being people with emotions and individual experiences that make us who we are and influence our behaviors, so asking a student to "leave it at the door" when coming into a class isn't realistic.

While this intervention was conducted in a science education context, we feel it is possible to tie SEL into many different academic disciplines. For those who aren't interested in integrating SEL with science but are interested in other academic areas, we encourage using our experience as inspiration to blend SEL with other academic subjects. In working directly with students, teachers are in a unique position to identify content which engages students' emotions leading to a high level of engagement. This understanding will be essential to the development of future interdisciplinary SEL approaches.

\section{DATA AVAILABILITY STATEMENT}

The deidentified raw data supporting the conclusions of this article will be made available by the authors, without undue reservation. The deidentified raw data supporting the conclusions.

\section{ETHICS STATEMENT}

Ethical review and approval was not required for the study on human participants in accordance with the local legislation and

\section{REFERENCES}

Banilower, E. R., Smith, P. S., Malzahn, K. A., Plumley, C. L., Gordon, E. M., and Hayes, M. L. (2018). Report of the 2018 National Survey of Science and Mathematics Education. NC: Chapel HillHorizon Research, Inc. Available at: http://horizon-research.com/NSSME/2018-nssme/research-products/ reports/technical-report (Accessed August 15, 2019).

Belfield, C., Bowden, A. B., Klapp, A., Levin, H., Shand, R., and Zander, S. (2015). The Economic Value of Social and Emotional Learning. J. Benefit Cost Anal. 6, 508-544. doi:10.1017/bca.2015.55

Bender, E. M., Gebru, T., McMillan-Major, A., and Shmitchell, S. (2021).On the Dangers of Stochastic Parrots: Can Language Models Be Too Big? In Proceedings of the 2021 ACM Conference on Fairness, Accountability, and Transparency FAccT '21. New York, NY, USA: Association for Computing Machinery, 610-623. doi:10.1145/3442188.3445922

Bledsoe, T. S., and Baskin, J. J. (2014). Recognizing Student Fear: The Elephant in the Classroom. Coll. Teach. 62, 32-41. doi:10.1080/ 87567555.2013.831022

Broughton, S. H., Sinatra, G. M., and Nussbaum, E. M. (2013). "Pluto Has Been a Planet My Whole Life!" Emotions, Attitudes, and Conceptual Change in Elementary Students' Learning about Pluto's Reclassification. Res. Sci. Educ. 43, 529-550. doi:10.1007/s11165-011-9274-x

Brown, B. A. (2021). Science in the City: Culturally Relevant STEM Education. Cambridge, MA: Harvard Education Press. doi:10.20935/al2014

CASEL (2015). Effective Social and Emotional Learning Programs: Middle and High School Edition. Chicago, Illinois. Available at: http:// secondaryguide.casel.org/. institutional requirements. Written informed consent from the participants' legal guardian/next of kin was not required to participate in this study in accordance with the national legislation and the institutional requirements.

\section{AUTHOR CONTRIBUTIONS}

JH and KR conceived and designed the study; JH, KR, EI, and GP contributed equally to writing the manuscript; $\mathrm{JH}$ and $\mathrm{KR}$ collected, cleaned, and analyzed the data.

\section{FUNDING}

Development of the DIFFERENT curriculum was funded in part by a grant from $\mathrm{H}$. Auerbach Memorial Fund.

\section{ACKNOWLEDGMENTS}

We would like to thank Janelle Johnson and Chanda Jefferson for their valuable feedback during the creation of the DIFFERENT curriculum and the four teachers and school district that invited us to pilot the DIFFERENT curriculum and the students who participated. We thank Celestron, LLC for sponsoring the NSTA workshops where the idea for the curriculum was first conceived and developed. Finally, we wish to thank Zachary Mayko for assistance with statistics and Jenny Keshwani for feedback and suggestions on this manuscript and helpful discussions about integrating SEL into science education.

CASEL (2013). Effective Social and Emotional Learning Programs: Preschool and Elementary School Edition. Chicago, Illinois. Available at: https://casel.org/ preschool-and-elementary-edition-casel-guide/.

Castano, C. (2012). Fostering Compassionate Attitudes and the Amelioration of Aggression through a Science Class. J. Res. Sci. Teach. 49, 961-986. doi:10.1002/ tea. 21023

Creswell, J. W. (2012). Educational Research: Planning, Conducting, and Evaluating Quantitative and Qualitative Research. 4th ed. Upper Saddle River, NJ: Pearson Education Inc.

Davis, R. H. (2004). The Age of Model Organisms. Nat. Rev. Genet. 5, 69-76. doi:10.1038/nrg1250

Dowdy, S., Wearden, S., and Chilko, D. (2004). Statistics for Research. 3rd ed. Hoboken, NJ: John Wiley \& Sons. doi:10.1002/0471477435

Durlak, J. A., Weissberg, R. P., Dymnicki, A. B., Taylor, R. D., and Schellinger, K. B. (2011). The Impact of Enhancing Students' Social and Emotional Learning: A Meta-Analysis of School-Based Universal Interventions. Child. Development 82, 405-432. doi:10.1111/j.1467-8624.2010.01564.x

Durlak, J. A., Weissberg, R. P., and Pachan, M. (2010). A Meta-Analysis of AfterSchool Programs that Seek to Promote Personal and Social Skills in Children and Adolescents. Am. J. Community Psychol. 45, 294-309. doi:10.1007/s10464010-9300-6

Forshaw, T. (2019). Designing Your Educational Design Work \#4-I Used to Think Now I Think. Medium. Available at: https://medium.com/stanford-d-school/ designing-your-educational-design-work-4-i-used-to-think-now-i-think8c33847bb839 (Accessed May 20, 2021).

Gebru, T. (2020). "Race and Gender," in The Oxford Handbook of Ethics of AI. Editors M. D. Dubber, F. Pasquale, and S. Das (Oxford University Press), 251-269. doi:10.1093/oxfordhb/9780190067397.013.16 
Goetz, T., Frenzel, A. C., Pekrun, R., and Hall, N. C. (2006). The Domain Specificity of Academic Emotional Experiences. J. Exp. Edu. 75, 5-29. doi:10.3200/ jexe.75.1.5-29

Harvard Graduate School of Education - Project Zero (2015). The "I Used to Think... Now I Think...” thinking routine. Available at: http://pz.harvard.edu/ resources/i-used-to-think-now-i-think (Accessed May 20, 2021).

IBM (2021). Watson Natural Language Understanding - Overview. Available at: https://www.ibm.com/cloud/watson-natural-language-understanding (Accessed May 20, 2021).

Immordino-Yang, M. H., and Damasio, A. (2007). We Feel, Therefore We Learn: The Relevance of Affective and Social Neuroscience to Education. Mind, Brain Educ. 1, 3-10. doi:10.1111/j.1751-228x.2007.00004.x

Ingram, E. (2019). A Mixed-Methods Study of Entomology Incorporation in u.S. Secondary Science Instruction. Dissertations Student Res. Entomol. Available at: https://digitalcommons.unl.edu/entomologydiss/60.

J. E. Zins (2004). Building Academic success on Social and Emotional Learning: What Does the Research Say? (New York, NY: Teachers College Press).

Jones, S. M., and Kahn, J. (2017). The Evidence Base for How We Learn: Supporting Students' Social, Emotional, and Academic Development. Consensus Statements of Evidence from the Council of Distinguished Scientists. Aspen, CO: Aspen Institute.

Katcher, A., and Teumer, S. (2006). A 4-year Trial of Animal-Assisted Therapy with Public School Special Education Students. Handbook animal-assisted Ther. Theor. foundations Guidel. Pract. 2, 227-242.

National Research Council (2012). A Framework for K-12 Science Education: Practices, Crosscutting Concepts, and Core Ideas. Washington, D.C: The National Academies Press.

NGSS Lead States (2013). Next Generation Science Standards: For States, by States. Washington DC, USA: National Academies Press. Available at: http://www. nap.edu/openbook.php?record_id=18290\&page=R16 (Accessed May 27, 2014).

Owens, M., Stevenson, J., Hadwin, J. A., and Norgate, R. (2012). Anxiety and Depression in Academic Performance: An Exploration of the Mediating Factors of Worry and Working Memory. Sch. Psychol. Int. 33, 433-449. doi:10.1177/ 0143034311427433

Pekrun, R., Goetz, T., Titz, W., and Perry, R. P. (2002). Academic Emotions in Students' Self-Regulated Learning and Achievement: A Program of Qualitative and Quantitative Research. Educ. Psychol. 37, 91-105. doi:10.1207/ s15326985ep3702_4
Pekrun, R., and Stephens, E. J. (2012). "Academic Emotions," in APA Educational Psychology Handbook: Individual Differences and Cultural and Contextual Factors (American Psychological Association), 3-31. doi:10.1037/13274-001

Taylor, R. D., Oberle, E., Durlak, J. A., and Weissberg, R. P. (2017). Promoting Positive Youth Development through School-Based Social and Emotional Learning Interventions: A Meta-Analysis of Follow-Up Effects. Child. Dev. 88, 1156-1171. doi:10.1111/cdev.12864

Thomas, D. R. (2006). A General Inductive Approach for Analyzing Qualitative Evaluation Data. Am. J. Eval. 27, 237-246. doi:10.1177/1098214005283748

Warr, P., and Downing, J. (2000). Learning Strategies, Learning Anxiety and Knowledge Acquisition. Br. J. Psychol. 91, 311-333. doi:10.1348/000712600161853

Zins, J. E., and Elias, M. J. (2007). Social and Emotional Learning: Promoting the Development of All Students. J. Educ. Psychol. consultation 17, 233-255. doi:10.1080/10474410701413152

Conflict of Interest: Solpugid Productions LLC (DBA The Bug Chicks) is a business owned by KR and JH. Solpugid Productions is the sole owner of the copyright to the DIFFERENT curriculum, which has been commercially available for purchase since 2019. The DIFFERENT curriculum was given to the school district in this study free of charge as part of a workshop series for students paired with a professional development experience for teachers.

The remaining authors declare that the research was conducted in the absence of any commercial or financial relationships that could be construed as a potential conflict of interest.

Publisher's Note: All claims expressed in this article are solely those of the authors and do not necessarily represent those of their affiliated organizations, or those of the publisher, the editors and the reviewers. Any product that may be evaluated in this article, or claim that may be made by its manufacturer, is not guaranteed or endorsed by the publisher.

Copyright (c) 2021 Ingram, Reddick, Honaker and Pearson. This is an open-access article distributed under the terms of the Creative Commons Attribution License (CC $B Y)$. The use, distribution or reproduction in other forums is permitted, provided the original author(s) and the copyright owner(s) are credited and that the original publication in this journal is cited, in accordance with accepted academic practice. No use, distribution or reproduction is permitted which does not comply with these terms. 